\section{An expression of body weight regulation in feeding behavior*}

\author{
D. A. BOOTH \\ Laboratory of Experimental Psychology, University of Sussex, Brighton, England
}

The variability of body weight at the time a rat starts a meal is less than its variability at the end of a meal. It is therefore possible that regulatory signals correlated with body weight more tightly control the duration of intermeal intervals (decay of satiety) than the amount eaten during a meal (initiation of satiety).

It is widely held that the precision with which the normal ad lib rat maintains a growth curve (even a constant body weight in females of some strains) is achieved by control of food intake. Some correlate of body weight, presumably reflecting the level of caloric reserves, is supposed to be measured to provide a long-term average error signal by which the neural feeding system can finely adjust caloric input to caloric expenditure. If this is the case, then the aspect of feeding behavior which mediates these fine adjustments should correlate with body weight. One question that arises is whether such control is expressed in the timing of meals or in their size. Reduction of caloric reserves to some threshold value could release acceptance of food and start a meal. Alternatively, anticipatory mechanisms could cut off acceptance and finish a meal when sufficient food has been taken to replete reserves to some threshold value. If one of these sorts of mechanism is appreciably more important than the other, the variability in body weight at that end of a

*This work is supported by the Medical Research Council. I thank G. M. McSherry and Miss D. B. Read for theit help.

Table 1

Group Mean Values of Average Body Weight and Range at Meal Start or Finish

\begin{tabular}{|c|c|c|c|c|c|c|c|}
\hline & \multirow[b]{2}{*}{$\mathrm{N}$} & \multicolumn{2}{|c|}{ At Start of Meal } & \multicolumn{2}{|c|}{ At End of Meal } & \multirow[b]{2}{*}{$\begin{array}{c}\text { Start Range } \\
\text { Minus Finish } \\
\text { Range } \\
\text { Divided by } \\
\text { Mean Range }\end{array}$} & \multirow[b]{2}{*}{$\mathrm{p}$} \\
\hline & & $\begin{array}{c}\text { Body } \\
\text { Weight } \\
\text { Average } \\
\text { (Grams) }\end{array}$ & $\begin{array}{c}\text { Body } \\
\text { Weight } \\
\text { Range } \\
\text { (Grams) }\end{array}$ & $\begin{array}{c}\text { Body } \\
\text { Weight } \\
\text { Average } \\
\text { (Grams) }\end{array}$ & $\begin{array}{l}\text { Body } \\
\text { Weight } \\
\text { Range } \\
\text { (Grams) }\end{array}$ & & \\
\hline Males & 12 & 431.2 & 8.1 & 432.4 & 14.6 & -0.496 & 0.02 \\
\hline Females & 6 & 241.2 & $3: 1$ & 241.8 & 4.2 & -0.284 & $<0.1$ \\
\hline
\end{tabular}

(ne end of meal was feedi followed by $10 \mathrm{~min}$ without the head being placed in the food jar.

A rat was weighed only once on an experimental day. Each rat was assigned to a meal-start or a meal-finish weighing on a given day. Start and finish weighings were made in the order SFFS in half of each sex and FSSF in the other half. Sometimes a meal did not occur in a day's observation period. The same assignment was then given the following day.

Urination or defecation was not generally observed to occur during a meal and did not occur during weighing.

\section{RESULTS}

Table 1 gives the group means for weighings at the beginnings of one pair of meals and at the ends of another couple of meals for each rat. The apparent difference between the two types of occasion in the average body weights presumably reflects the food and water taken during a meal, although these differences were not statistically reliable. The variable of primary interest here is the body-weight range--the difference between the rat's weights on the pair of occasions on which it was weighed at one end of a meal. This was calculated for each rat (group means are given in Table 1). The difference between the meal-start range and the meal-finish range was then divided by the mean of the two ranges for each rat. This provided a normalized measure of variability ( 0.78 times the coefficient of variation for the population of range differences). The group means of this ratio are given in the table, with the reliability of their difference from zero by two-tailed correlated $t$ tests. In both sexes, the body-weight range at the end of a meal was greater than the body-weight range at the beginning of a meal. Combining the groups, this difference in variability was reliable with a $\mathrm{p}<.01$.

$$
\text { p }
$$
better correlation of body weight with the ending of an intermeal interval than with the ending of a meal reflects caloric reserves in adipose tissue, the gut, or elsewhere, or whether it is amplified or even generated by variations in prandial drinking. 